\title{
Emotional Intelligence, Anger and Coping Strategy among Chronic Kidney Disease Patients
}

\author{
Anganabha Baruah ${ }^{1 *}$
}

\section{ABSTRACT}

The aim of the study was to study the emotional intelligence, anger and coping strategy among chronic kidney (CKD) disease patients. A sample of 60 (30 male, 30 female) selected from various hospitals of Pune city. The tools used for the study were Emotional intelligence scale (Thingujam and Ram, 2000), STAXI-II (Speilberger, 1999) and Ways of coping questionnaire (Lazarus and Folkman, 1988). After the data collection statistical analysis was done by Pearson product-moment correlation and't test'. The result found that there is a negative correlation between emotional intelligence and trait anger. It also found a positive correlation between problem focused coping and emotional intelligence. This study also suggested that female patients are higher on emotional intelligence and problem focused coping strategy than male patients. The findings of the study could provide a better understanding of chronic kidney patients' mental state and their well-being.

Keywords: CKD, emotional intelligence, Pune.

India is a very vast country. Along with the present era of globalization, the life of individual has also developed to a great extent as in life style, career etc. Yet these advantages have led to a highly stressful life and many emotional disturbances, as well as many critical health problems. Among them, chronic kidney disease (CKD) is a worldwide public health problem and is now recognized as a common condition that is associated with an increased risk of many mental health problems. In India's 1 billion populations, it is found that there are 7.84 million CKD patients. (S.C Dash, S.K Agarwal 2006). The most common causes of CKD are diabetes mellitus, hypertension. Together, these cause approximately $75 \%$ of all adult cases. In a study by Mark (2005), it was found that persons coping with kidney disease commonly cite feelings, such as anger, fear, depression, anxiety, confusion, frustration and helplessness. This type of mental problems is mainly due to the long onset and poor prognosis of the disease. So it can be helpful to know about their emotional intelligence, their anger and how they cope with daily

\footnotetext{
${ }^{1}$ Counsellor, Observation Home For Boys-II, Delhi, Bamunimaidam, Ananda Nagar, House No-15, Guwahati, Assam

*Responding Author

(c) 2016 I A Baruah; licensee IJIP. This is an Open Access Research distributed under the terms of the Creative Commons Attribution License (http://creativecommons.org/licenses/by/2.0), which permits unrestricted use, distribution, and reproduction in any Medium, provided the original work is properly cited.
} 
stressors. And the findings can be used to provide them a less painful life, healthy family atmosphere and positivity for well being of them. So that with better psychological conditions they can recover in a better way. In a study by Close and Davies (1986) on emotional difficulties in diabetes mellitus, it was found that $28 \%$ people had appreciable emotional or behavioral difficulties and $12 \%$ considered themselves 'possibly depressed', poorer self esteem, and a greater external locus of control. Pedrites and Furnham (2000) showed that female showed high emotional intelligence and it was supported by Katyal and Awasthi (2005), on the gender difference of emotional intelligence among adolescent female showed higher EI than male. In exploring the relationship of emotional intelligence with physical and psychological health functioning by Tsaousis and Nikolau (2005), it was observed that EI is negatively associated with poor general health and other health related behaviors, such as smoking, drinking whereas, Haffey and Kerry (2006) found that Child reports of adjustment and emotional intelligence and indicated that higher emotional intelligence scores may predict better overall adjustment, as well as better functioning in terms of internalizing and externalizing behaviours. A research done by Deshields, Taylor(1989) it was found that the chronic patient groups differed significantly from the non patient controls in reporting more anger in general, greater frequency of anger experiences, and a tendency to express anger more outwardly..Polonsky (2002)focused on emotional and quality-of-life aspects of diabetes management, it was that found patients with diabetes commonly feel overwhelmed, frustrated, or "burned out" by the daily hassles of disease management and by the unending, often burdensome self-care demands, it was found that both medical and psychosocial aspects of diabetes may negatively affect health related quality of life; in turn, impaired health related quality of life may negatively influence diabetes selfmanagement. The latest research by Staicu and Cutov (2010) about the negative effects of anger and hostility, it was found that there is a connection between anger, hostility and aggressiveness and various health risks and the intervention for healing or preventing these diseases should not only be pharmacological, but also psychological, therapists should insist on ways of managing these behaviours in order to prevent diseases and any kind of risk that they could involve. Tietz and Vidmar (1972) found about the impact of coping styles on the control of juvenile diabetes that the reactions to the onset of diabetes did influence the styles of coping with fears, anxieties and guilt.The study by Genco and Grossy (1999), it was found that emotion focused coping measures of stress associated with financial strain and distress manifest as depression, are significant risk indicators for more severe periodontal disease in adults in an age-adjusted model in which male, smoking, diabetes mellitus etc. are significant risk factors. Findings occurred in research done by Keefe and Afflack (2003) that female chronic pain patients showed more problems focused coping than men, and were less likely than men to report negative mood. Harwood and Wilson (2008) shows that the stressors experienced in the early stages of CKD are different than those experienced by individuals on dialysis. and in the same year, Varonica (2008) studied about coping strategies of mothers who have a child with chronic illness, determine mothers' understanding of disease before and after diagnosis, assess mothers' perceived needs for support when coping with their child's illness it was found that early diagnosis of illness improved mothers' coping. Jordan and Ashkanasy (2005) found that 
emotional intelligence moderates employees' emotional reactions to job insecurity and their ability to cope with associated stress. In this respect, low emotional intelligence employees are more likely than high emotional intelligence employees to experience negative emotional reactions to job insecurity and to adopt negative coping strategies. Ciarrochi and Chan (2001) studied about low emotional intelligence and mental illness; it was found that low emotional intelligence may contribute to problems in interpersonal relationships and in coping with stress.

\section{METHODS}

\section{Hypotheses}

i. The female CKD patient would be score higher in problem focused coping strategy than male patients.

ii. The female CKD patients would score higher on emotional intelligence than male patients.

iii. The male CKD patients with diabetes would score higher on emotion focused coping than male patients without diabetes.

iv. There is a negative correlation between emotional intelligence and trait anger.

v. There is a positive correlation between emotional intelligence and problem-focused coping strategies.

\section{Variable and tools}

The variables of the study are emotional intelligence, anger and coping strategies.

\section{The tools used in the study were:}

Emotional Intelligence Test_The test used in assessing sample in the present study is the Indian adaptation (by Thingujem N.S and Usha Ram, 2000) of the emotional intelligence scale by Schutte having 33 items.

The State Trait Anger Expression Inventory - 2_ STAXI-2 is a 57 items inventory ,which consists of a 4-point scales ,measures the intensity of anger as an emotional state (state anger) and the disposition to experience angry feelings as a personality trait(trait anger). It is given by Speilberger (1999).

Ways of Coping Questionnaire, The test used for assessing the present study is the English version of 'ways of coping questionnaire’ by Lazarus and Folkman (1988).

\section{Sample}

The samples used in the study are selected by purposive sampling method. 60 patients of chronic kidney disease, 30 patients with diabetes (15 male, 15 female) and 30 patients without diabetes (15 male, 15 female) from various hospitals of Pune city. Their age range is from 45-55 years. Most of the patients were multilingual, and spoke Marathi, Hindi and English. The patients were from various socio-economic statuses, ranging from lower middle class to upper middle class. The female patients were mostly housewives, whereas, the male patients were from different occupations. 


\section{Method of Data Collection}

The individual administration of the test was done on the chronic kidney disease patient with diabetes and without diabetes. Firstly, the repo was formed and all possible information about the test was given and patients were asked to fill up the personal data sheet with all relevant information about them. Then proper instructions were given. All doubts were clarified. There was no time limit given, but had instructed to complete the test as soon as possible. First the emotional intelligence test, then the anger inventory and coping questionnaire was administered serially.

\section{Statistical Analysis}

The statistical analysis in this study would include the t test used to study the gender difference and difference between patients with diabetes and patient without diabetes.The Pearson's Product-Moment correlation to study the correlation among emotional intelligence, trait anger and coping strategies.

\section{RESULTS}

Table 1 shows the gender difference in problem focused coping among the patients

\begin{tabular}{|c|c|c|c|c|c|c|}
\hline Variables & Gender & Mean & SD & df & t value & $\begin{array}{c}\text { Cohen's } \\
\text { D }\end{array}$ \\
\hline \multirow{2}{*}{$\begin{array}{c}\text { Problem } \\
\text { focused } \\
\text { coping }\end{array}$} & male & 30 & 3.09 & \multirow{2}{*}{58} & 8.24 & 1.18 \\
\cline { 2 - 4 } & female & 35 & 5.12 & & \\
\hline
\end{tabular}

The table 1 shows the obtained values in problem focused coping. It shows that the obtained value of female patients $(\mathrm{M}=35, \mathrm{SD}=5.12)$ is higher $(\mathrm{t}=8.24, \mathrm{p}<0.05)$ than male patients in problem focused coping. According to Cohen (1988), the values up to 0.2 are small effect, 0.5 is medium effect and above 0.8 is large effect. So the obtained value is large size, which shows (Cohen's $\mathrm{D}=1.18$ ) a very high difference among the groups. In this, the hypothesis 1 stating that the 'female patient would be score higher in problem focused coping strategy than male patients' is accepted.

Table 2 shows the gender difference in emotional intelligence among patients

\begin{tabular}{|c|c|c|c|c|c|c|}
\hline Variable & Gender & Mean & SD & df & t value & $\begin{array}{c}\text { Cohen's } \\
\text { D }\end{array}$ \\
\hline \multirow{2}{*}{$\begin{array}{c}\text { Emotional } \\
\text { intelligence }\end{array}$} & Female & 110.57 & 8.71 & 58 & 7.69 & 1.98 \\
\cline { 2 - 5 } & Male & 100.33 & 7.70 & & \\
\hline
\end{tabular}

Table 2 shows that the value of emotional intelligence of female patients $(\mathrm{M}=110.7, \mathrm{SD}=8.71)$ is higher $(t=7.69, \mathrm{p}<0.05)$ than male patients $(\mathrm{M}=100.33$, $\mathrm{SD}=7.70)$. The Cohen's $\mathrm{d}$ shows that there is large effect size (Cohen's $D=1.98$ ) and a very high difference among the two 
groups. So the hypothesis 2 that 'the female patients would score higher on emotional intelligence than male patients' is accepted.

Table 3 shows the difference between male patient with diabetes and without diabetes

\begin{tabular}{|c|c|c|c|c|c|c|}
\hline Variable & Gender & Diabetes & Mean & SD & df & t value \\
\hline $\begin{array}{c}\text { Emotion } \\
\text { focused } \\
\text { coping }\end{array}$ & male & No & 32.8 & 4.24 & 28 & 0.59 \\
\cline { 2 - 6 } & male & Yes & 33.7 & 4.60 & & \\
\hline
\end{tabular}

The table 3 indicates that the obtained value of male patients with diabetes $(\mathrm{M}=32.8$, SD $=$ $4.24)$ is higher $(\mathrm{t}=0.59, \mathrm{p}>0.05)$ than male patient without diabetes in emotion focused coping. However, the difference is not significant. Hence, the hypothesis 3 that 'the male patients without diabetes would score higher on emotion focused coping than male patients with diabetes' is rejected.

Table 4 shows the correlations among emotional intelligence; trait anger and problem focused coping strategy

\begin{tabular}{|c|c|c|c|}
\hline Variables & E.I & t. anger & PFC \\
\hline E.I & 1 & & \\
\hline T. Anger & -.47 & 1 & 1 \\
\hline PFC & .29 & -.071 & \\
\hline
\end{tabular}

According to the findings obtained from table 4, states that there is negative correlation between emotional intelligence and trait anger $(r=-0.47)$, so here the hypotheses 4 that 'there is a negative correlation between emotional intelligence and trait anger' is accepted. Which means when EI will increase the trait anger may decrease. It also shows a positive correlation between problem focused coping strategy and emotional intelligence $(r=0.29)$. By this hypothesis 5 that 'there is a positive correlation between emotional intelligence and problem-focused coping strategies' is also accepted. It states that increase in EI will signify an increase in problem focused coping. However, a very low negative relationship $(r=-.071)$ was obtained between problem focused coping and trait anger.

\section{DISCUSSION}

After analyzing the obtained findings, it was found that there is a negative correlation between emotional intelligence and trait anger and a positive relation between emotional intelligence and problem focused coping. Findings also suggest that there is a significant gender difference in emotional intelligence and problem focused coping. 
The first hypothesis is that the female patient would score higher on problem focused coping than male patient. This hypothesis was also accepted in the present study. Similar findings occurred in research done by Keefe and Afflack (2003) that female chronic pain patients showed more problems focused coping than men, and were less likely than men to report negative mood. In this study this hypothesis could be accepted because despite the stereotypical belief that women are very emotional, actually they could be more rational than male at least for the present study and they may focus more on the problem than seeking for emotional support. The result showed a significant difference between female score and male score $(t=8.24)$. Similarly, the second hypothesis is that the female patient would score higher in emotional intelligence than male patients. In a research done by Pedrites and Furnham (2000) showed that female showed high emotional intelligence because they scored high on the "social skills" factor of measured trait EI. However, it was also demonstrated that males believed they had higher EI than female. Another study by Katyal and Awasthi (2005), on the gender difference of emotional intelligence among adolescent female showed higher EI than male. The hypotheses may be accepted because according to our previous hypotheses it was proved that there is a positive relation between emotional intelligence and problem focused coping and that female scored higher on problem focused coping. Hence the result relatively showed a high emotional intelligence of female. At the same time, female are found to be more rational than men in some studies. The result showed a significant difference between male and female scores on emotional intelligence $(t=7.69)$.

The third hypothesis is that the male patients without diabetes would score higher on emotion focused coping than male patients with diabetes. This hypothesis was accepted in the study by Genco and Grossy (1999), it was found that emotion focused coping measures of stress associated with financial strain and distress manifest as depression, are significant risk indicators for more severe periodontal disease in adults in an age-adjusted model in which male, smoking, diabetes mellitus etc are significant risk factors. However, in this study, this hypothesis is rejected. The difference between male patient with diabetes and without diabetes was not significant ( $\mathrm{t}=0.59$ ). This finding is supported by DeCoster and Cummings (2004), suggested that patient with type 2 diabetes shows various coping methods, not a particular one is dominant. This hypothesis could be rejected because having two chronic illnesses at a time may not affect the coping style of patients, there way of coping can vary because of individual differences.

The fourth hypothesis is that there is a negative correlation between emotional intelligence and trait anger. In this study, this hypothesis is accepted. Similar result was found in the study by Jordan and Ashkanasy (2005), which is mentioned in the second chapter that people with lower emotional intelligence are more likely to experience negative emotional reactions as anger, frustration to job insecurity than higher emotionally intelligent employees. Other studies as by Salovey and Mayer (1999), Matheson and Jahoda (2005) are also in support of the hypothesis. This hypothesis is accepted as the result showed ( $r=-0.47)$ a negative correlation between emotional intelligence and trait anger. Similarly, the fifth hypothesis states that there is a positive correlation between emotional intelligence and problem focused coping strategy and this 
hypothesis is accepted in this study. Another study by Nolen-Hoeksema and Grayson (1999) supported this hypothesis as it was found that the quality of parenting family environment and emotional intelligence is associated with children's problem-focused coping behaviors. Again some other studies mentioned in the second chapter as Cirrochi and Chan (2001) supported this hypothesis. This current study showed $(r=0.29)$ a positive correlation between emotional intelligence and problem focused coping strategy.

It was already proved by various studies that there is a strong relation between mental health and chronic diseases. In a study by Perlman and Finkelstein (2004), it was found that health related quality of life in dialysis patients is low. Another study by Stewart and Greenfield (1989) about Functional Status and Well-being of Patients with Chronic Conditions, it was found that Patients with multiple conditions showed greater decrements in functioning and well-being than those with only one condition. So this study can prove to be very useful for betterment of mental health of patients with chronic diseases.

\section{IMPLICATION OF THE STUDY}

The obtained results in the present study can be very useful in clinical or diagnostic field to assess the need of the patient or to move the treatment from one phase to another. High level of emotional regulation is related with the low production of stress hormone (Wirtz and Kanel 2005).As we can see that the obtained results are somewhat different than the stereotypical notion that men are more rational than women. In this study it was found that women are higher on emotional intelligence and problem focused coping than men, because, another finding of the study is that emotional intelligence and problem focused coping are positively correlated. In clinical purpose, this study suggests that the mental state of female patients may be stronger than male patients and there is a possibility of better and faster recovery of female than male. They would be more motivated and have a better understanding of the problems they face. The male's emotional intelligence skills could be developed by using various techniques or therapies. Another finding suggests that having diabetes does not have an additional effect on patient's psychology. That is may be because having two chronic diseases at the same time does not significantly impair the functioning of patients. In industrial field also, female employees could be given upper hand to make important decisions of business dealings or development. But before generalizing the result, it is very important to conduct the study on a larger sample and with samples from different sectors. This study may provide an effective way to make desired changes and an important base for further research on these variables.

\section{REFERENCES}

Ashkanasy, N. M., \& Daus, C. S. (2002). Emotion in the workplace: The new challenge for managers. Academy of Management Executive, 16(1), 76-86. Greenwood publishing books: Westport. 
Ciarrochi, J. V., Chan, A. Y., \& Caputi, P. (2000). A critical evaluation of the emotional intelligence construct. Personality and Individual Differences. Wiley publication: New York

Cohen, J. (1988). Statistical power analysis for the behavioural sciences (2nd edition). Hillsdale, NJ: Erlbaum.

Dashfield AK, Taylor MB, Cleaver JS, Farrow D (1989). Comparison of caudal steroid epidural with targeted steroid placement during spinal endoscopy for chronic sciatica: a prospective, randomized, double-blind trial. British Journal of Anasthesia; 94:514-519.

Davies, M., Stankov, L., \& Roberts, R.D. (1998). Emotional Intelligence: In search of an elusive construct. Journal of Personality and Social Psychology, 75, 989-1015. Basic Books: London.

DeCoster, V.A., Cummings, S., (2004). Coping With Type 2 Diabetes: Do Race And Gender Matter? Social Work. Health. US National Library of Medicine.

Fajans, S., Bell, G.I., Polonsky, K. (2002). Molecular mechanisms and clinical pathophysiology of maturity-onset diabetes of the young. Journal of Medicine; 345(13):971-980.

Genco, R.J., Grossi, S.G., (1999). Relationship of Stress, Distress, and Inadequate Coping Behaviours to Periodontal Disease. Journal of periodontology. American academy of periodontology.

Haffey (2006). The Relationship between Emotional Intelligence and Psychological Adjustment of Children with Cancer. University of Auburn. Unpublished dissertation.

Harwood, L., Wilson, B. (2008). Stressors and coping in individuals with chronic kidney disease. Journal of Nephrology Nursing. Resource library: USA.

Katyal, S., Avasthi, E., (2005). Gender Differences in Emotional Intelligence Among Adolescents of Chandigarh. Journal of Human Ecology. 17(2): 153-155.

Keefe, F.J., Afflack, G., (2003). Living with rheumatoid arthritis: the role of daily spirituality and daily religious and spiritual coping. Journal of pain. US National Library of Medicine.

Mayer, J.D., Salovey, P. (1999). What is emotional intelligence? In P. Salovey \& D. Sluyter (Eds.), Emotional development and emotional intelligence: Implications for educators (pp. 3-31). Basic Books: London.

Nolen-Hoeksema, S., Larson, J., \& Grayson, C. (1999). Explaining the gender difference in depressive symptoms. Journal of Personality and Social Psychology, 77, 1061-1072.

Perlman RL, Finkelstein FO, Liu L, et al. (2005).Quality of life in chronic kidney disease (CKD): a cross-sectional analysis in the Renal Research Institute-CKD study. Journal of Kidney disease. Jones and Bartlett Publishers: London.

Petrides, K., \& Furnham, A. (2001). Trait emotional intelligence: Psychometric investigation with reference to established trait taxonomies. European Journal of Personality, 15(6), 425-448. Jones and Bartlett Publishers: London.

Staicu, M.L., Cutov, M. (2010). Anger and health risk behaviours. Journal of Medicine and Life. University of Medicine and Pharmacy. 
Stewart, A. L., Greenfield, S., Hays, R. D., Wells, K. B., Rogers, W. H., Berry, S. D., McGlynn, E. A.,\&Ware, J. E. (1989). Functional status and well-being of patients with chronic conditions. Journal of the American Medical Association, 262, 907-913.

Tietz, W., Vidmar, J.T., (1972). The Impact of Coping Styles on the Control of Juvenile Diabetes. Journal of Psychiatric Medicine. 7:75-81.

Tsaousis, I., Nikolau, I., (2005). Exploring the Relationship between Physical and Psychological Health. Stress and Health. Wiley publication: New York.

Varronica, M. (2008). Mothers' coping in chronic childhood illness: the effect of presymptomatic diagnosis of vesicoureteric reflux. Journal of Advanced Nursing. Wiley Publication: New York.

Wirtz, P.H., Kanel, R.V. (2005). Low Social Support and Poor Emotional Regulation Are Associated with Increased Stress Hormone Reactivity to Mental Stress in Systemic Hypertension. Journal of the Journal of Clinical Endocrinology \& Metabolism. The Endocrine Society: USA.

\section{DECLARATION}

I hereby declare that the research work entitled "Emotional Intelligence, Anger and Coping Strategy among Chronic Kidney Disease Patients” is on the basis of the relevant source materials and the field work that I carried out in Pune. The data collected and conclusions drawn in the dissertation are my own and they are not previously published. The books and articles referred are listed I the reference list and the quotations are acknowledged. 